\title{
Quality of care for people with dementia in general hospitals: national cross-sectional audit of patient assessment
}

\author{
Authors: Renata Souza, ${ }^{\mathrm{A}}$ Aarti Gandesha,,${ }^{\mathrm{B}}$ Chloe Hood, ${ }^{\mathrm{C}}$ Robert Chaplin, ${ }^{\mathrm{D}}$ John Young, ${ }^{\mathrm{E}}$ Peter Crome ${ }^{\mathrm{F}}$ and Mike J Crawford
}

There have been recent reports of poor quality care in the National Health Service in the UK, and older people with dementia are particularly vulnerable. This study aims to examine the quality of assessment of people with dementia admitted to hospital. Cross-sectional case-note audit of key physical and psychosocial assessments was carried out in 7,934 people with dementia who were discharged from 206 general hospitals. Most people had no record of a standardised assessment of their cognitive state (56.8\%, 95\% confidence interval $[\mathrm{CI}]=55.8-58.0)$ or functioning (74.2\%, 95\% CI = 73.2-75.1). Information from carers was documented in $39.0 \%$ of cases $(95 \% \mathrm{CI}=37.9-40.1)$. There was considerable variation across hospital sites. Key assessments were less likely when people were admitted to surgical wards. Assessments fall well below recommended standards especially with regard to social and cognitive functioning. Problems are particularly marked on surgical wards.

KEYWORDS: Dementia, hospital admission, audit, assessment, quality improvement

\section{Introduction}

Currently, 800,000 people in the UK have dementia ${ }^{1}$ with over a million expected within the next 10 years. ${ }^{2}$ Over a third of people in acute hospital beds have cognitive impairment, most of whom have dementia or delirium. ${ }^{3}$ Concerns have repeatedly been expressed about the quality of inpatient care that people with dementia receive, ${ }^{4-7}$ including the quality of assessment. ${ }^{8}$

Authors: Adeputy programme manager, College Centre for Quality Improvement, Royal College of Psychiatrists, London, UK; ${ }^{\text {B }}$ programme manager, College Centre for Quality Improvement, Royal College of Psychiatrists, London, UK; Cprogramme manager, College Centre for Quality Improvement, Royal College of Psychiatrists, London, UK; Dconsultant psychiatrist, College Centre for Quality Improvement, Royal College of Psychiatrists, London, and Oxford Health Foundation NHS Trust, Oxford, UK; Ehonorary consultant geriatrician, Academic Unit of Elderly Care and Rehabilitation, University of Leeds, Leeds, UK; Fhonorary professor, Department of Primary Care and Population Health, University College London, London, UK; ${ }^{G}$ director, College Centre for Quality Improvement, Royal College of Psychiatrists, London, and Imperial College London, UK
Admission to a general hospital can have a detrimental effect on a person with dementia, as a result of unfamiliar surroundings and disruption to daily routines, as well as direct cognitive effects of physical illness. ${ }^{9}$ Frail older people admitted to general hospitals should receive a comprehensive assessment focusing on medical and psychological conditions, and functional capacity. ${ }^{10}$ Key components include nutritional state, presence of pain, cognitive state and general functioning. It has been argued that high-quality assessment of needs leads to better care, decreases length of stay and reduces readmissions. ${ }^{11,12}$

People with dementia may not be able to communicate their care needs effectively, so relatives and carers may be able to provide this vital information. It is therefore important that the formal care assessment documentation prompts the collection of this information. ${ }^{13}$

The national audit of dementia was commissioned in response to concerns about the quality of care that people with dementia receive in general hospitals. ${ }^{8}$ The objectives were to measure the proportion of people with dementia who receive high-quality assessment, examine variation in the quality of assessment across different hospital sites, and identify clinical and demographic factors associated with the likelihood that key assessments are completed.

\section{Method}

\section{Study sample}

The national audit of dementia was set up in 2008 to assess the quality of care provided to people with dementia admitted to general hospitals in England and Wales. In 2010 chief executives and directors of nursing from 238 eligible hospitals in England and Wales were asked to participate. Each participating hospital was required to perform a retrospective audit of 40 case notes of patients with dementia who had been discharged between 1 September 2009 and 28 February 2010. The period could be extended from 1 May 2009 to 30 April 2010 for those sites with slow recruitment. The inclusion criteria were an admission to hospital for at least 4 days and a recorded diagnosis or history of dementia. Case notes were examined only for the first admission for people who were admitted more than once. The case-note audit tool is described in Box 1. In addition to auditing 40 case notes, each hospital was required to reaudit the first five cases using a different auditor to establish interrater reliability for each of the questions in the tool. Data 


\section{Box 1. Case-note audit tool.}

Audit data were collected using a data extraction tool designed to collect data on the quality of care received in hospitals specifically for the study. It was based on a review of standards published in national reports, guidelines, and recommendations from professional bodies and organisations representing service users and carers. ${ }^{3,10,13-15} \mathrm{~A}$ draft was reviewed by members of the project steering group which included members of the Royal College of Nursing, British Geriatrics Society, Royal College of General Practitioners, Royal College of Physicians, Royal College of Psychiatrists, University of Worcester Association for Dementia, Bradford Institute for Health Research, the Alzheimer's Society and a service user representative. The audit tool was piloted on 34 case notes from 7 hospitals in England. The tool was modified before national rollout, incorporating feedback received on its content and layout.

The questions in the audit tool collected information about patients' admission, care planning and delivery, and discharge and assessment. It included whether five assessments that cover physical and psychosocial needs had been completed; these were assessments of nutrition, cognitive state, pain and functioning, and the collection of information from the carer about the person with dementia.

An assessment of nutritional state was considered to have been completed if there was any record that this had been carried out in the patient notes. To be judged as having included a measure of cognitive state there had to be evidence of a standardised assessment such as the Mini-Mental State Examination ${ }^{16}$ or Abbreviated Mental Test. ${ }^{17}$ Any reference to the patient being asked about physical pain, and a response recorded, was sufficient for this standard to be met. Information collected from a carer, next of kin or a person who knew the patient well was considered to have been completed if there was a record of any personal information about the patient that had been recorded in a specified section of the case notes. An assessment of functioning had been completed if a standardised instrument, such as the Barthel index, ${ }^{18}$ had been used and a score recorded. There were additional questions on demographic and clinical characteristics; including age, gender, ethnicity, length of stay, type of ward, and the types of residence they were admitted from and discharged to. When patients were treated on more than one ward in their admission, the type of ward where they spent most of their time in hospital was recorded. Hospitals were advised to complete the case-note audit with input from the local audit lead, the lead for dementia or a senior clinician working in this area, and staff who normally undertake audits of case notes such as audit department staff and junior doctors.

on dependent variables from 891 sets of case notes showed that interrater reliability ranged from $\kappa=0.48$ ( $95 \%$ confidence interval $[\mathrm{CI}]=0.42-0.54$ ) for assessment of pain to $\kappa=0.78$ $(95 \%$ CI $=0.74-0.82)$ for assessment of cognitive state. The five assessments selected for this paper are the most robust ones, those that have the greatest interrater reliability.

Data were submitted via a secure online survey hosted by the Royal College of Psychiatrists' webpage. Unique usernames and passwords were provided to each participating hospital and a unique hospital code assigned to ensure that the data submitted were anonymous and confidential, and could be identified only by the audit's project team. The online data entry system required all fields to be filled in; hence there were no missing data

\section{Data analysis}

The case-note audit included over 15 standards and in this report we focus on 5 key components of the assessment of people with dementia. These were selected before examining associations with explanatory variables because they had been highlighted in standards of care for people with dementia and had acceptable levels of interrater reliability. Data recorded on the case note audit tool allowed each of the five assessments to be rated as present or absent. Before analysis, data were checked so that duplicate cases and patients who had stayed in hospital for fewer than 4 days could be excluded from the sample. Data were analysed using SPSS, version 20.0. ${ }^{19}$

Appropriate univariate tests were performed to investigate the relationships between dependent variables (assessments of nutrition, cognitive state, pain, functioning, and the collection of information from the carer about the person with dementia) and possible explanatory factors (gender, ethnicity, type of ward, place of admission and place of discharge). The student's $t$-test for parametric data was used to investigate the relationships between categorical variables (assessments of nutrition, cognitive state, pain and functioning, and the collection of information from the carer about the person with dementia) and possible continuous parametric predictor variables (age and length of stay). Due to the number of statistical tests, Bonferroni's correction was applied and the level of significance was set at $p<0.01$. Relationships between possible explanatory and dependent variables were then entered into a binary logistic regression analysis to identify predictors for whether each of the five types of assessment was completed. The continuous variables age and length of stay were recoded into categorical variables to facilitate the regression analysis.

Analyses were initially conducted on the total sample of people admitted with dementia, including those who died while in hospital. These analyses were repeated for sensitivity, excluding those who died.

The national audit of dementia was supported by the Healthcare Quality Improvement Partnership, who were contracted by the Department of Health in England to deliver outcome-focused quality improvement programmes.

\section{Results}

Of the 238 eligible hospitals in England and Wales, 206 (86.6\%) took part in the audit. Case-note data were collected from 7,934 patient admissions. The median number of audited case notes submitted by each hospital was 40 (range 10-48).

The mean age of the patients in the sample was 83.9 years $(\mathrm{SD}=7.7)$, and ranged from 34 to 110 . Of these, $2,851(35.9 \%)$ were male and 5,083 (64.1\%) female. Most of the sample $(5,974,75.3 \%)$ were white British, with 441 (5.6\%) from other ethnic groups (the ethnicity of 1,519 [19.2\%] patients was not reported). Most patients in the sample were cared for in specialist older adult wards $(3,467,43.7 \%)$, followed by medical wards $(2,583,32.6 \%)$ and orthopaedic/surgical wards $(1,192,15.0 \%)$. At the time of their admission to hospital, 4,147 
Table 1. Proportion of assessments completed during the inpatient admission of 7,934 patients with dementia and range in proportion completed across 206 hospital sites.

\begin{tabular}{|c|c|c|c|}
\hline Assessment type & $\begin{array}{l}\text { Total number } \\
\text { completed (mean } \\
\text { percentage) }\end{array}$ & $\begin{array}{l}95 \% \text { confidence } \\
\text { intervals for the } \\
\text { mean percentage }\end{array}$ & $\begin{array}{l}\text { Range of mean percentage } \\
\text { completed across the } \\
206 \text { hospital sites }\end{array}$ \\
\hline Assessment of nutritional state & $5,536(69.8)$ & $68.8-70.8$ & $2.6-100$ \\
\hline Standardised assessment of functioning & $2,051(25.9)$ & $24.9-26.8$ & $0-100$ \\
\hline Standardised assessment of cognitive state & $3,422(43.1)$ & $42.0-44.2$ & $5.7-100$ \\
\hline Assessment of pain & $5,736(72.3)$ & $71.3-73.3$ & $10.5-100$ \\
\hline Evidence of carer being included in the assessment & $3,094(39.0)$ & $37.9-40.1$ & $0-100$ \\
\hline All five assessments completed & $364(4.6)$ & $4.2-5.1$ & $0-55.6$ \\
\hline
\end{tabular}

(52.3\%) of patients came from their own home or a relative/ carer's home, and when discharged from hospital, 2,153 (27.1\%) patients in the sample returned to their own home or a care home. Of patients in the sample, 1,211 (15.3\%) died during their stay in hospital.

The number and proportion of case notes that had information about the five elements of assessment are provided in Table 1. There was considerable variation in the completion of all five assessments across the 206 hospital sites.

\section{Factors associated with assessment completion}

The univariate analysis presented below contains only the statistically significant associations between patients' sociodemographic factors and the likelihood of completion of the five individual assessments. Longer length of stay was significantly associated with a greater likelihood of all five assessments being completed (mean lengths of stay between 1.9 and 5.7 days longer for the patients with completed assessments). Admission to a specialist ward for care of older adults predicted a $7.45-12.7 \%$ greater likelihood of assessments of nutrition, functioning, cognitive state and carer assessment than admission to a surgical ward. However, surgical wards were $9.63 \%$ more likely to complete a pain assessment than specialist older adult wards. A patient's age was not associated with completion of assessments. Female gender predicted a 3.18\% higher likelihood of assessment of pain. Admission from home rather than residential care predicted an $8.8 \%$ greater completion rate assessment of cognition and a $5.6 \%$ greater rate of assessment of functioning. Discharge home rather than to residential care predicted a $3.0 \%$ higher likelihood of completion of assessment of functioning and a $13.2 \%$ greater rate of assessment of cognition. Patients from black and minority ethnic groups were $4.56 \%$ more likely to receive an assessment of functioning but $10.71 \%$ less likely to have a cognitive assessment.

When the analysis was repeated to exclude the 1,211 (15.3\%) patients in the sample who died during their stay in hospital, results were broadly the same, with the exception that black and minority ethnic groups were no longer more likely than white British people to receive an assessment of functioning. Results of the binary logistic regression analysis (Table 2) confirmed associations between the likelihood of a range of assessments being completed and the type of ward on which the patient was treated, with lower levels of all types of assessments being completed on surgical wards, except assessment of pain which was more likely to have been completed.

\section{Discussion}

Results from this study clearly demonstrate that people with dementia who are admitted to general hospitals are not being assessed in accordance with recommended practice. Of 7,934 patient notes included in the audit, only 364 (4.6\%) had evidence of all five key assessments. The results also highlight major variation between hospitals in the assessments received by patients. For two of the five types of assessment, functioning and the collection of information from a carer, all patients in some hospitals had recorded information on these aspects of care, and in other hospitals none of the records included evidence that these aspects of care had been assessed. Psychosocial assessments (functioning, cognitive state and the collection of personal information about the person with dementia) were less likely to be carried out than physical assessments (pain and nutrition). Those treated on surgical wards were less likely to receive four out of five of the aspects of assessment compared with those admitted to specialist older adult wards.

\section{Strengths and limitations of the study design}

The case-note audit tool was designed from evidence-based standards that were developed by the consensus of a team of professionals and service users following a comprehensive literature review, and underwent several revisions and a pilot stage. We were able to analyse data from $86.6 \%$ (206) eligible hospitals in England and Wales, representing 99.0\% (150) of eligible trusts and health boards. With the majority of hospitals taking part, we are confident that these findings are generalisable to all hospitals in these two countries.

A number of limitations need to be taken into account when interpreting the study findings. Assessment could be accepted as having taken place only where information had been recorded in the patient's notes: a limitation of all casenote studies. To aid accurate and reliable data collection by the local medical and nursing staff collecting it, we provided detailed information. The accuracy of data was checked by a second auditor in a sample of 891 case notes, and the level of 
Table 2. Factors associated with assessments documented among 7,934 patients adjusted for age, gender, ethnicity and length of stay.

\begin{tabular}{|c|c|c|c|c|c|c|c|c|c|c|}
\hline \multirow[t]{3}{*}{ Setting } & \multicolumn{2}{|c|}{ Nutrition } & \multicolumn{2}{|c|}{ Functioning } & \multicolumn{2}{|c|}{ Cognitive state } & \multicolumn{2}{|c|}{ Pain } & \multicolumn{2}{|c|}{ Carer assessment } \\
\hline & Odds & $p$ value & Odds & $p$ value & Odds & $p$ value & Odds & $p$ value & Odds & $p$ value \\
\hline & Ratio & & Ratio & & Ratio & & ratio & & ratio & \\
\hline \multicolumn{11}{|l|}{ Type of ward: } \\
\hline Specialist older adult & - & - & - & - & - & - & - & - & - & - \\
\hline Surgical & 0.62 & $<0.001$ & 0.68 & $<0.001$ & 0.34 & $<0.001$ & 1.87 & $<0.001$ & 0.75 & $<0.001$ \\
\hline Medical & 1.01 & 0.941 & 0.75 & $<0.001$ & 0.60 & $<0.001$ & 1.05 & 0.480 & 0.83 & 0.002 \\
\hline \multicolumn{11}{|l|}{ Admitted from: } \\
\hline Own/relative/carer's home & - & - & - & - & - & - & - & - & - & - \\
\hline Residential care & 1.03 & 0.823 & 0.83 & 0.050 & 0.26 & $<0.001$ & 0.90 & 0.227 & 1.06 & 0.519 \\
\hline \multicolumn{11}{|l|}{ Discharged to: } \\
\hline Own/relative/carer's home & - & - & - & - & - & - & - & - & - & - \\
\hline Residential care & 0.95 & 0.576 & 0.94 & 0.556 & 0.68 & $<0.001$ & 1.01 & 0.935 & 1.03 & 0.768 \\
\hline
\end{tabular}

interrater reliability was in the moderate range. ${ }^{20}$ We cannot, however, rule out the possibility that the way that staff recorded information in the case notes had an impact on reliability.

The study focused on five key aspects of patient assessment and did not cover all aspects of a comprehensive assessment identified by the British Geriatrics Society. ${ }^{10}$ The topics that were chosen for this analysis were selected based on the key findings of the first round of the national audit of dementia, ${ }^{20}$ and were identified as key assessments for people with dementia in general hospitals.

\section{Implications for services}

The results from this study highlight the need for services to evaluate the way that people with dementia are currently assessed when they are admitted to general hospitals.

People with dementia are especially vulnerable to poor care, particularly if not able to communicate their needs or if they need help with eating and drinking. It is therefore essential that assessments identify whether an individual is likely to have dementia and what care needs they might have, using relevant information from a relative or carer.

The likelihood of patients receiving an assessment of nutritional state is shown to increase with longer length of stay. To identify care needs of patients, clinicians should be mindful that the assessments are carried out on admission or as soon as the patient is well enough. The deficiencies of care identified in this audit has led to several national bodies issuing new guidance that targets improvements to systems of care and workforce skills in relation to dementia, eg organisations can sign up to the Dementia Action Alliance (www.dementiaaction.org.uk/joint_work/the_right_care), in order to work toward achieving five main goals in dementia care. These are: improving the inpatient environment; the knowledge, skills and attitudes of the workforce; the ability to identify and assess cognitive impairment; appropriate support on discharge; and the use of a person-centred care plan that involves families and carers. Future iterations of the audit will enable the uptake and effects of these new national initiatives to be quantified.

Results from a staff survey conducted as part of the audit ${ }^{20}$ showed that qualified nurses on surgical/orthopaedic wards felt that their training was less sufficient than that of their colleagues working on specialist older adult wards and medical wards. ${ }^{21}$ These deficiencies in staff training may have an impact on the care that is delivered to patients in hospital, including key assessments being carried out. Therefore these need to be addressed by services, particularly those relating to the psychosocial needs of patients.

\section{Implications for research}

This study found that psychosocial assessments were less likely to be carried out than physical assessments, and that people admitted to a surgical/orthopaedic ward were less likely to receive a comprehensive assessment than those admitted to a specialist older adult ward. Further research is needed to identify barriers to conducting psychosocial assessments, especially on surgical/orthopaedic wards. Assessment practice on specialist older adult wards should be studied to identify better practice elements and examine how these could be transferred to other wards.

Previous studies have shown that routine comprehensive assessment maximises rehabilitation potential, leading to positive outcomes, ${ }^{12}$ and are particularly important for people with dementia who may have difficulty with communicating their needs. Future studies should be conducted to establish the impact of completing key assessments on outcomes for patients hospitalised with dementia.

\section{Acknowledgements}

The authors would like to acknowledge the contributions of the Royal College of Physicians, the Royal College of Nursing, the Royal College of General Practitioners, the Alzheimer's Society and the British Geriatrics Society, which were partners in the national audit of dementia. 


\section{References}

1 Alzheimer's Society. Dementia 2012: a national challenge. London: Alzheimer's Society, 2012. www.alzheimers.org.uk/site/scripts/ download_info.php?downloadID=821 [Accessed 4 August 2014].

2 Health Service Ombudsman. Care and compassion? Report of the health service ombudsman on ten investigations into NHS care of older people. London: The Stationery Office, 2011. www.ombudsman.org. $\mathrm{uk} /$ care-and-compassion/downloads [Accessed 4 August 2014].

3 Department of Health. Living well with dementia: a national dementia strategy. London: Department of Health, 2009. www.gov. uk/government/publications/living-well-with-dementia-a-nationaldementia-strategy [Accessed 4 August 2014].

4 Alzheimer's Society. Counting the cost: caring for people with dementia on hospital wards. London: Alzheimer's Society, 2009. www.alzheimers.org.uk/site/scripts/documents_info. php?documentID=1199 [Accessed 4 August 2014].

5 House of Commons All-party Parliamentary Group on Dementia. The $£ 20$ billion question: an enquiry into improving lives through cost-effective dementia services. London: House of Commons, 2011. www.alzheimers.org.uk/site/scripts/download_info. php?fileID=1207 [Accessed 4 August 2014].

6 NHS Confederation. Acute awareness: improving hospital care for people with dementia. London: NHS Confederation, 2010. www. nhsconfed.org/ /media/Confederation/Files/Publications/ Documents/Dementia_report_Acute_awareness.pdf [Accessed 4 August 2014].

7 Francis R. Report of the Mid Staffordshire NHS Foundation Trust public inquiry. London: The Stationery Office, 2013. www.midstaffspublicinquiry.com/report [Accessed 4 August 2014].

8 Royal College of Psychiatrists. Report of the national audit of dementia: care in general hospitals 2011. London: Healthcare Quality Improvement Partnership, 2011. www.rcpsych.ac.uk/PDF/ NATIONAL\%20REPORT\%20-\%20Full\%20Report\%201201122.pdf [Accessed 4 August 2014].

9 Department of Health. Everybody's business: integrated mental health services for older adults. A service development guide. London: $\mathrm{DH}, 2005$. http://webarchive.nationalarchives.gov. uk/20060715141954/http://olderpeoplesmentalhealth.csip.org.uk/ everybodysbusiness [Accessed 4 August 2014].

10 British Geriatrics Society. Comprehensive assessment of the frail older patient in hospital, 2010. www.bgs.org.uk/index.php/ topresources/publicationfind/goodpractice/195-gpgcgassessment [Accessed 4 August 2014].
11 Ellis G, Langhorne P. Comprehensive geriatric assessment for older hospital patients. Br Med Bull 2005;71:45-59.

12 Ellis G, Whitehead M, Robinson D et al. Comprehensive geriatric assessment for older adults admitted to hospital: meta-analysis of randomised controlled trials. BMJ 2011;343:d6553.

13 National Institute for Health and Care Excellence. Dementia: Supporting people with dementia and their carers in health and social care. CG42. London: NICE, 2006. www.nice.org.uk/guidance/cg42/resources/guidance-dementia-pdf [Accessed 4 August 2014].

14 Royal College of Psychiatrists. Who cares wins. Improving the outcome for older people admitted to the general hospital. Guidelines for the development of Liaison Health Services for older people. London: RCPsych, 2005. www.rcpsych.ac.uk/pdf/ whocareswins.pdf [Accessed 4 August 2014].

15 National Audit Office. Improving services and support for people with dementia. London: The Stationery Office, 2007. www.nao.org.uk/ report/improving-services-and-support-for-people-with-dementia/ [Accessed 4 August 2014].

16 Folstein MF, Folstein SE, McHugh PR. Mini-mental state. A practical method for grading the cognitive state of patients for the clinician. J Psychiatr Res 1975;12:189-98.

17 Hodkinson HM. Evaluation of a mental test score for assessment of mental impairment in the elderly. Age Ageing 1972;1:233-8.

18 Mahoney F, Barthel D. Functional evaluation: the Barthel Index. $M d$ Med J 1965;14:61-5.

19 IBM Corp. IBM SPSS Statistics for Windows, Version 20.0. Armonk, NY: IBM Corp, 2011.

20 Royal College of Psychiatrists. National audit of dementia (care in general hospitals). National results: enhanced audit checklists and questionnaires. London: RCPsych, 2011. www.rcpsych.ac.uk/pdf/ National\%20data\%20table\%20-\%20website\%20hqip.pdf [Accessed 4 August 2014].

21 Gandesha A, Souza R, Chaplin R, Hood C. Adequacy of training in dementia care for acute hospital staff. Nursing Older People 2012;24:26-31.

Address for correspondence: Dr R Chaplin, College Centre for Quality Improvement, Royal College of Psychiatrists, 21 Prescot Street, London E1 8BB. Email: rchaplin@cru.rcpsych.ac.uk 